This article was downloaded by: [Costanza Scaffidi Abbate]

On: 06 July 2013, At: 06:03

Publisher: Routledge

Informa Ltd Registered in England and Wales Registered Number: 1072954 Registered

office: Mortimer House, 37-41 Mortimer Street, London W1T 3J H, UK

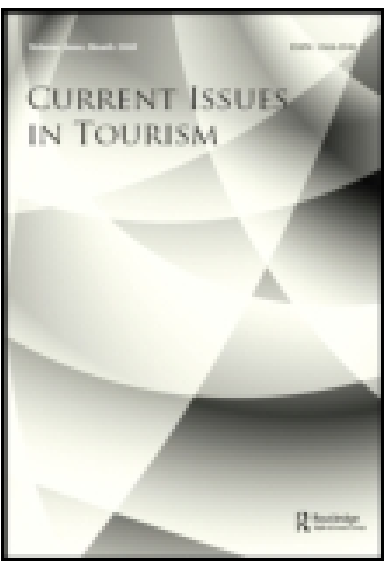

\title{
Current Issues in Tourism
}

Publication details, including instructions for authors and subscription information:

http:/ / www. tandfonline.com/ loi/ rcit20

\section{Motivation and personality traits for choosing religious tourism. A research on the case of Medjugorje}

\author{
Costanza Scaffidi Abbate ${ }^{a} \&$ Santo Di Nuovo ${ }^{b}$ \\ a Department of Psychology, University of Palermo, Palermo, \\ Italy \\ ${ }^{b}$ Department of Formative Processes, University of Catania , \\ Catania , Italy \\ Published online: 08 J an 2013.
}

To cite this article: Costanza Scaffidi Abbate \& Santo Di Nuovo (2013) Motivation and personality traits for choosing religious tourism. A research on the case of Medjugorje, Current Issues in Tourism, 16:5, 501-506, DOI: 10.1080/13683500.2012.749844

To link to this article: http:// dx.doi.org/ 10.1080/ 13683500.2012.749844

\section{PLEASE SCROLL DOWN FOR ARTICLE}

Taylor \& Francis makes every effort to ensure the accuracy of all the information (the "Content") contained in the publications on our platform. However, Taylor \& Francis, our agents, and our licensors make no representations or warranties whatsoever as to the accuracy, completeness, or suitability for any purpose of the Content. Any opinions and views expressed in this publication are the opinions and views of the authors, and are not the views of or endorsed by Taylor \& Francis. The accuracy of the Content should not be relied upon and should be independently verified with primary sources of information. Taylor and Francis shall not be liable for any losses, actions, claims, proceedings, demands, costs, expenses, damages, and other liabilities whatsoever or howsoever caused arising directly or indirectly in connection with, in relation to or arising out of the use of the Content.

This article may be used for research, teaching, and private study purposes. Any substantial or systematic reproduction, redistribution, reselling, loan, sub-licensing, systematic supply, or distribution in any form to anyone is expressly forbidden. Terms \& Conditions of access and use can be found at http://www.tandfonline.com/page/termsand-conditions 


\title{
CURRENT ISSUES IN TOURISM LETTER
}

\section{Motivation and personality traits for choosing religious tourism. A research on the case of Medjugorje}

\author{
Costanza Scaffidi Abbate ${ }^{\mathrm{a} *}$ and Santo Di Nuovo ${ }^{\mathrm{b}}$ \\ ${ }^{a}$ Department of Psychology, University of Palermo, Palermo, Italy; ${ }^{b}$ Department of Formative \\ Processes, University of Catania, Catania, Italy
}

(Received 4 September 2012; final version received 12 November 2012)

\begin{abstract}
Religion has long been a primary motivation for journeys and it is considered the oldest non-economic reason for travelling. The purpose of this paper is to investigate the reasons tourists choose to travel to sacred sites, with the specific aim of discovering relationships between personality traits and motivations for religious travel. Participating in the research were 679 Italian travellers to Medjugorje sanctuary, who completed the travel motivation scale and big five questionnaire. The results show that motivation is focused prevalently on the need for discovery in men and socialisation in women. Multiple regression analyses demonstrated that personality traits are predictive of motivation factors differently for males and females.
\end{abstract}

Keywords: religious tourism; motivations; personality traits; big five questionnaire

\section{Introduction}

Why people travel to sites of religious significance is an important question in studying tourism. The role of religion as a catalyst for increasing travel, the importance of collecting and disseminating best practices for encouraging it, as well as practical tools for improving the management and sustainability of religious destinations were highlighted in an international conference on 'Tourism, religions and dialogue of cultures' (UNWTO, 2008).

One type of religious travel is the pilgrimage. There are evident links between tourism and pilgrimage in terms of both the journey and the experience of community; indeed, Turner and Turner (1978) famously claimed that 'a tourist is half a pilgrim, if a pilgrim is half a tourist' (p. 20). According to the United Nation World Tourism Organization (UNWTO, 2008), nearly 300 million pilgrims visit religious sites every year all over the world, representing an expanding economic sector. For the tourism industry, pilgrims are generally treated like general tourists because pilgrims often have the same needs as general tourists and visit tourist-frequented places, such as museums, cafes, and shops, in addition to the religious sites. It can be stated that the pilgrimage is experiencing ' $\mathrm{a}$ marked resurgence' (Digance, 2003) and is as popular now as it has been in the past.

According to Shackley (2001), the pilgrim wishes to have a spiritual experience using travel as an act of fortification of faith. This can be accomplished through spiritual retirement in a sanctuary or through participation in some religious event such as mass or

*Corresponding author. Email: costanza.scaffidi@unipa.it 
some other religious activity. Some people, probably, travel to maintain an identity, others to satisfy the feelings of nostalgia, some to experience the transcendent, and some to fulfill the requirements of particular faith-based groups, for example, the journey to Mecca for devout Muslims. Religious tourists, today, are considered 'pilgrims of modernity', choosing holy sites for reasons other than religious ones (MacCannell, 1976). Many different motivations, not of a religious nature, drive people to engage in pilgrimage journeys, particularly in the context of the worries and concerns typical of the modern world.

A dispute has arisen in several scientific journals concerning the tourist who searches for modernity or authenticity. Sharpley (2008) has pointed out the spiritual dimension of tourism by examining the relationship between authenticity and tourism and considering the ways in which tourists look to their heritage and history in searching for the authentic roots of their identities. Religious travel may be an occasion for meditation and may provide experiences that afford individuals the potential to reconstruct meanings related to identity. Indeed, Cohen (1979) proposed that tourists often choose elective spiritual centres that are external to the mainstream of their native societies and cultures.

In such scenarios, personality factors may play a relevant role. In fact, the purpose of several recent research studies has been to explain the connection between personality and touristic choices (Berno \& Ward, 2005). Consistent with this line of research, our work aimed to study tourists' decisions to visit a religious site, with the specific purpose of discovering the relationship between motivations for religious travel and personality. The focus of the study is a particular sacred place that has recently received worldwide attention: Medjugorje, where it is said that the Virgin Mary has been appearing since 1981.

\section{Objectives}

This study aimed to explore some motivations of religious tourists and to assess the relationship between these motivations and personality traits.

\section{Method \\ Participants}

Participants were Italian tourists who had chosen a travel package for the Marian Sanctuary of Medjugorje (Bosnia-Herzegovina). The participants were selected with the help of a specialised travel agency and data were collected before or during the trip. ${ }^{1}$ The sample was composed of 679 subjects, with 244 males and 435 females. The imbalanced gender distribution reflects the usual composition of groups travelling to religious sites (Jansen, 2012).

The age range was $18-63$ years $($ Mean $=36.92 ; \mathrm{SD}=13.24)$, with $37.8 \%$ aged $18-$ 30 years, $42.0 \%$ aged $31-50$ years, and $20.2 \%$ over 50 years of age. Education was middlehigh ( $>13$ years of schooling for $62.74 \%$ of the participants). Prevalent occupations $(>5 \%$ of participants) included students $(26.8 \%)$, employees $(21.8 \%)$, autonomous workers $(18.26 \%)$, teachers $(8.84 \%)$, and retirees $(6.77 \%)$.

\section{Instruments}

The instruments administered were as follows:

1. The Travel Motivation Survey was devised by Figler, Weinstein, Sollers, and Devan (1992) and adapted for use in Italy by Maeran (2000). The questionnaire explores, 
by means of 35 items on a 5-point Likert scale, seven motivational categories: culture, self-seeking, sensation-seeking, status, sociality, relaxation, and nature. In a previous principal components factor analysis, using Varimax rotation, the items of the scale loaded on three main factors accounted for $40 \%$ of the total variance and were labelled Curiosity and discovery, Out-of-routine, and Self and sociality. The curiosity and discovery factor includes items that measure a wish to see unknown sites and curiosity for different cultural experiences. The out-of-routine factor includes items that measure a wish to have unusual experiences and to escape from one's daily routines. The third factor, self and sociality, includes items that measure the extent to which travel is seen as a means of rediscovering one's self through socialisation. Cronbach alphas for the three factor scores were $0.82,0.64$, and 0.68 , respectively.

We used an instrument designed for general tourism, adapted for Italian samples, and consequently the lack of specific instruments suitable for religious travelling.

2. The big five questionnaire (BFQ, Costa \& McCrae, 1992) measures five personality factors: energy/activity, agreeableness/cooperation, conscientiousness, emotional stability, and openness to experience. The Italian edition, adapted by Caprara, Barbaranelli, and Borgogni (1993), was used for our study.

\section{Results}

The factors of the travel motivation survey showed in our sample results were similar to those found for general tourists in Italian samples (Perussia \& Viano, 2002). A covariance analysis showed that both gender and educational level are relevant in determining scores for the three factors (Table 1). Males' aims are more oriented towards discovery, while females' motivations tend towards the self and sociality factor. Gender does not influence the out-of-routine factor. Educational level has a positive influence on all three motivational factors.

Some significant differences in motivations were found among groups divided by age. For the out-of-routine and self and sociality factors, the extreme age groups have significantly higher scores $\left(F_{2,676}=9.25, p<0.001 ; F_{2,676}=22.81, p<0.001\right.$, respectively $)$. No significant age differences were found for the curiosity/discovery factor.

Table 1. Differences between genders in touristic motivations and covariance analysis, including years of schooling as covariate.

\begin{tabular}{|c|c|c|c|c|c|c|c|}
\hline \multirow[b]{3}{*}{ Motivation } & \multirow[b]{3}{*}{ Gender } & \multirow[b]{3}{*}{ Mean } & \multirow[b]{3}{*}{ Std dev. } & \multicolumn{4}{|c|}{ Analysis of covariance } \\
\hline & & & & \multirow{2}{*}{$\begin{array}{c}\text { Gender } \\
F(1,1,676)\end{array}$} & \multirow{2}{*}{$\begin{array}{c}\text { Educ. } \\
\text { (Covariate) }\end{array}$} & \multicolumn{2}{|c|}{$p$} \\
\hline & & & & & & Gende & Educ. \\
\hline \multirow[t]{2}{*}{ Curiosity and discovery } & M & 3.32 & 0.86 & 9.73 & 4.11 & $<0.01$ & 0.04 \\
\hline & $\mathrm{F}$ & 3.08 & 0.91 & & & & \\
\hline \multirow[t]{2}{*}{ Out of routine } & M & 1.40 & 0.48 & 0.94 & 7.89 & 0.33 & 0.01 \\
\hline & $\mathrm{F}$ & 1.38 & 0.47 & & & & \\
\hline \multirow{2}{*}{ Self and socialisation } & M & 2.92 & 0.72 & 9.99 & 12.73 & $<0.01$ & $<0.01$ \\
\hline & $\mathrm{F}$ & 3.13 & 0.73 & & & & \\
\hline
\end{tabular}


Table 2. Personality traits predicting motivation to travel. Standardised coefficient derived from multiple regressions for each factor of the motivation test.

\begin{tabular}{lccccccc}
\hline & \multicolumn{5}{c}{ Motivation factors } \\
\cline { 2 - 5 } \cline { 6 - 8 } BFQ traits & Discover & Out-of-Rout. & Socialis. & & Discover & Out-of-Rout. & Socialis. \\
\cline { 2 - 4 } \cline { 6 - 8 } & $0.34^{*}$ & 0.12 & $0.47^{*}$ & & $0.29^{*}$ & $0.53^{*}$ & $0.37^{*}$ \\
Energy & $0.35^{*}$ & $0.46^{*}$ & $0.65^{*}$ & & 0.05 & 0.09 & $0.48^{*}$ \\
Agreeableness & 0.06 & $0.40^{*}$ & $0.41^{*}$ & & $0.30^{*}$ & -0.02 & 0.12 \\
Consciousness & 0.05 & 0.19 & 0.06 & & -0.07 & -0.03 & 0.00 \\
Openness & 0.18 & -0.23 & $-0.61^{*}$ & & $0.38^{*}$ & $0.37^{*}$ & 0.01 \\
\hline
\end{tabular}

${ }^{*} p(t)<0.05$.

Percentages of participants exceeding the cut-off for the BFQ Italian sample $(T=65$, i.e. 1.5 s.d. over the mean), indicating a 'very high' position for each variable, were calculated (reference, for each gender: BFQ Italian standardisation, Caprara et al., 1993). A very small percentage of subjects, both males and females, has high scores on the energy $(1.76 \%$ overall) and openness $(2.95 \%)$ factors, which is different from the expected trend for tourists aiming to travel to new and distant destinations. A comparison between genders shows a significant relation (chi-square $=17.73, \mathrm{df}=5, p=0.003$ ). Gender differences are evident particularly for the conscientiousness and emotional stability factors, with higher percentages of females than males who score above the cut-off $(3.45 \%$ vs. $0.41 \%$ and $7.36 \%$ vs. $2.46 \%$, respectively).

The following multiple regression analyses, separated by gender, aimed to explore what personality traits, measured by BFQ scores, result predictors of the factors for motivating travel. Table 2 shows that the energy/activity trait is predictive for almost all motivation factors in both genders (except for the out-of-routine motivation factor for males). Agreeableness predicts all motivational factors in males, and the self and sociality factor in

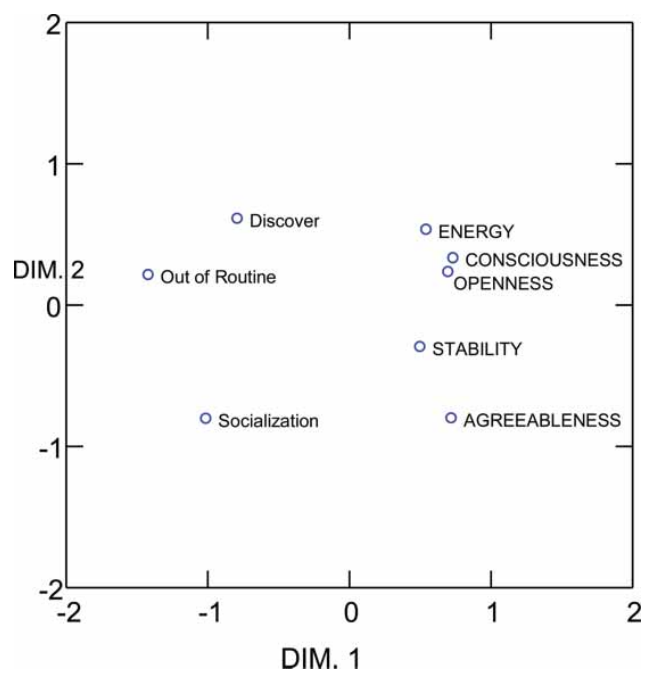

Figure 1. Multidimensional scaling of motivation variables and personality traits (Kruskal method). 
females. Conscientiousness predicts the out-of-routine and self and sociality factors in males, and the curiosity and discovery factor in females. The openness to experience trait is linked to self and sociality factor scores in males and to curiosity and discovery and out-of-routine factor scores in females. Emotional stability is predictive of any of the motivational variables in either gender.

To test the general relation among variables, monotonic multidimensional scaling using the Kruskal method was performed on the correlation matrix for the whole sample. The results are graphically shown in Figure 1.

The model has a good fit (stress of final configuration: 0.06; proportion of explained variance: 0.98 ). Two dimensions clearly emerged from the analysis: personality $v s$. touristic motivation (Dimension 1) and energy/activity linked to curiosity and discovery vs. self and sociality linked to agreeableness and cooperation (Dimension 2). These two dimensions sharply differentiate religious touristic travellers.

\section{Conclusions}

The purpose of this study was to explore motivations for choosing travel to a religious destination (i.e. Medjugorje), and the relationship between such motivation and personality traits. Several studies have analysed the profile of pilgrims travelling to different religious destinations, including Lourdes (Pieper \& Van Uden, 1994), the Holy Land (CollinsKreiner \& Kliot, 2000), and Fatima (Ambrosio, 2001). According to Lanquar (2008), religious tourism in general is changing, so that today, it should not be described in a stereotypical way. Regarding the Christian pilgrimage, the attitude towards tourism seems to be mostly determined by the characteristics of each pilgrimage; For example, Millán, Pérez, and Carranza (2012) have described differences between the profiles of participants in pilgrimages to Santiago de Compostela or to El Rocío.

Certainly, religious travel is multifaceted, with different kinds of aims and activities included in a single trip, and relevant differences among people according to gender and age. The gender differences in participation that were found in our sample are reflective of general religious tourism trends; also, young people, particularly those participating in religious groups, frequently go on pilgrimages to sites like Medjugorje. Bartoluci and Martinovic (1999) also found a great number of young people among the pilgrims to Medjugorje, as well as elderly and sick people.

While in general no differences have been found with the motivation for not religious tourism, the findings of our research showed that both gender and age differentiate religious travellers along certain psychological variables. Male travellers to Medjugorje seem to be characterised primarily by a motivation focused on the need for discovery, while women show a greater desire for socialisation and openness to other people.

Finally, the results also indicate that, among religious tourists, those who have a more marked energetic personality (described as a confident and enthusiastic approach to the various circumstances of life) are motivated by a need for discovery, while the agreeableness/cooperation trait is connected to the need for socialisation. Openness to experience, that is willingness to accept new ideas and others' values and feelings, is linked to self and sociality in males and to curiosity and discovery and out-of-routine factors in females.

These findings seem to provide some information about the motivations and personality traits of travellers to a religious site like Medjugorje which is also useful for planning and managing the marketing of tourism. Understanding, in more detail, why people choose this kind of destination, and the types of personalities that such travellers have could be useful not only for fulfilling pilgrims' expectations but also for promoting specific marketing 
campaigns and may help religious sites to develop new services and partnerships for attracting more visitors.

\section{Note}

1. Dr Donatella Armeli cooperated in the administration of the instruments and in building the database.

\section{References}

Ambrosio, V. (2001). Os turistas/Peregrinos em Fátima. Série Documentos, 2, 69-75.

Bartoluci, M., \& Martinovic, S. (1999). The state and the perspectives of the development of religious tourism in Medjugorje. Acta Turistica, 11, 171-198.

Berno, T., \& Ward, C. (2005). Innocence abroad: A pocket guide to psychological research on tourism. American Psychologist, 60, 593-600, doi:10.1037/0003-066X.60.6.593.

Caprara, G.V., Barbaranelli, C., \& Borgogni, L. (1993). BFQ-big five questionnaire. Firenze: O.S.

Cohen, E. (1979). A phenomenology of tourist experience. Sociology, 13, 179-201.

Collins-Kreiner, N., \& Kliot, N. (2000). Pilgrimage tourism in the holy land: The behavioural characteristics of Christian pilgrims. GeoJournal, 501, 55-67.

Costa, P.T., \& McCrae, R.R. (1992). Revised NEO personality inventory (NEO-PI-R) and NEO fivefactor inventory (NEO-FFI) manual. Odessa, FL: Psychological Assessment Resources.

Digance, J. (2003). Pilgrimage at contested sites. Annals of Tourism Research, 30, 143-59.

Figler, M.H., Weinstein, A.R., Sollers, J.J., \& Devan, B.D. (1992). Pleasure travel (tourist) motivation: A factor analytic approach. Bulletin of the Psychonomic Society, 2, 113-116.

Jansen, W. (2012). Old routes, new journeys: Reshaping gender, nation and religion in European pilgrimage. In C. Notermans \& W. Jansen (Eds.), Gender, nation and religion in European pilgrimage (pp. 1-18). Farnham: Ashgate.

Lanquar, R. (2008). Tourism and religions: A contribution to the dialogue among religions, cultures and civilizations. International Conference on Tourism, Religions and Dialogue of Cultures (pp. 197-204). Cordoba, Spain, 29-31 October 2007. Madrid: World Tourism Organization.

MacCannell, D. (1976). The tourist: A new theory for the leisure class. New York: Schoken Books.

Maeran, R. (2000). Motivazione ed esperienza turistica: uno strumento di misura. In P.G. Gabassi and M. Togni (Eds.), Proceedings VIII National Congress "Psicologia e Turismo, Viaggiare per Conoscersi" (pp. 111-120). Milano: CUEM.

Millán, G., Pérez, L., \& Carranza, R. (2012). Analysis of the pilgrim profile in Spain: Two case studies. International Journal of Applied Science and Technology, 2(4), 23-29.

Perussia, F., \& Viano, R. (2002). Dimensioni psicosociali del turismo: Una sintesi. In C. Stroppa (Ed.), Mutamento culturale e modelli di turismo (pp. 65-71). Roma: Bulzoni.

Pieper, J., \& Van Uden, M. (1994). Lourdes: A place of religious transformations? The International Journal for the Psychology of Religion, 4(2), 91-104.

Shackley, M. (2001). Managing sacred sites: Services provision and visitor experience. London: Continuum Press.

Sharpley, R. (2008). Tourism, tourists and society. Huntington: Elm Publications.

Turner, V., \& Turner, E. (1978). Image and pilgrimage in Christian culture. New York: Columbia University Press.

UNWTO. (2008). International Conference on Tourism, Religions and Dialogue of Cultures, Cordoba, Spain, 29-31 October 2007. Madrid: World Tourism Organization. 